\title{
Response of the Flat Reinforced Concrete Floor Slab with Openings under Cyclic In-Plane Loading
}

\author{
Eden Shukri Kalib and Yohannes Werkina Shewalul \\ Faculty of Civil and Environmental Engineering, Jimma Institute of Technology, Jimma University, Jimma, Ethiopia \\ Correspondence should be addressed to Yohannes Werkina Shewalul; yesoro.work@gmail.com
}

Received 4 August 2021; Accepted 17 September 2021; Published 24 September 2021

Academic Editor: Giovanni Garcea

Copyright (C) 2021 Eden Shukri Kalib and Yohannes Werkina Shewalul. This is an open access article distributed under the Creative Commons Attribution License, which permits unrestricted use, distribution, and reproduction in any medium, provided the original work is properly cited.

\begin{abstract}
The responses of flat reinforced concrete $(\mathrm{RC})$ floor slabs with openings subjected to horizontal in-plane cyclic loads in addition to vertical service loads were investigated using nonlinear finite element analysis (FEA). A finite element model (FEM) was designed to perform a parametric analysis. The effects of opening sizes $(7 \%, 14 \%, 25 \%$, and $30 \%$ of the total area of the slab), opening shapes (elliptical, circular, L-shaped, T-shaped, cross, and rectangular), and location on the hysteretic behavior of the floor slab were considered. The research indicated that openings in RC floor slabs reduce the energy absorption capacity and stiffness of the floor slab. The inclusion of $30 \%$ opening on the floor slab causes a $68.5 \%, 47.3 \%$, and $45.6 \%$ drop in lateral load capacity, stiffness, and lateral displacement, respectively, compared to the floor slab with no openings. The flat RC floor slab with a circular opening shape has increased efficiency. The placement of the openings is more desirable by positioning the openings at the intersection of twocolumn strips.
\end{abstract}

\section{Introduction}

As a primary horizontal structural element of building structures, the floor slab is susceptible to loads in and out of a plane, which are mostly attributable to lateral loads $[1,2]$. It is therefore important to consider the combined effect of inplane and out-of-plane loads when designing a slab of concrete for a building. It resists vertical forces for most of its design life. However, the floor structure can withstand horizontal seismic stresses during an earthquake that could last only between 10 and 100 seconds. It is termed a diaphragm during this brief period when the floor structure must withstand both gravity and horizontal forces [1].

The performance of the diaphragm action of the floor slab is controlled primarily by its in-plane stiffness. The floor diaphragm is considered rigid if it translates only on a plane and rotates as a rigid body about the vertical axis, whereas a flexible diaphragm is one in which the lateral force distribution to vertical lateral load resisting elements is depending on the tributary area. Finally, a stiff diaphragm is one that behaves in between the two [3-5]. An experimental and analytical investigation was carried out at Lehigh University [6] to identify in-plane seismic behavior of floor diaphragm with scaled models representing a portion of a floor system in a building structure with various loading and support conditions. The diaphragm forces were applied in the plane of the floor system, both monotonically and cyclically. The hysteresis behavior was identified after the floor slab system experienced inelastic deformation.

In many structures, a reasonable estimate of the inertial force distribution can be achieved by assuming that the slabs act as a rigid diaphragm, but for structures with large openings and with noncompact shapes, diaphragm deformation of the floors must be explicitly considered in the analysis. Many building codes, including Euro code and ACI, have stated that failing to account for floor diaphragm flexibility when estimating the seismic response of floor diaphragms with large openings and noncompact or highly elongated in-plane shapes can lead to errors.

The effect of openings on the seismic capacity of floor diaphragm has been investigated by several researchers, and it has been confirmed that the presence of openings on the 
floor diaphragm results in a substantial decrease in load capacity of the floor diaphragm. Previous research has indicated that the inelastic seismic response of the RC floor diaphragm is highly affected by the presence of openings, especially when cracking and yielding in the floor system. A micro FEM approach was used to identify the effect of opening size and out-of-plane loading on the inelastic seismic behavior of beam-supported floor diaphragm with the opening [7]. Openings or reentrant corners in the diaphragm must be properly placed and adequately reinforced [8].

In building, damage due to earthquake generally initiates at locations of structural weakness, and these weaknesses are mostly found at discontinuities in mass, stiffness, and strength of vertical and horizontal lateral load resisting elements. Nowadays because of architectural aesthetics and ventilation, floor slabs with openings have been used in many building structures. Besides building services, including stairways, elevators, air ducts, and pipes also need to pass through floor slabs, and in this process, there is weakness induced in the floor slab. Since it is necessary to understand the behavior of floor slabs with openings, different analytical studies based on experimental tests were conducted. But still, there is limited knowledge on the characteristics of RC floor slabs with different locations, shapes, and sizes of openings.

In the present study, flat RC floor slabs responses with different opening sizes, opening shapes, and locations of the openings under horizontal direct cyclic loading and vertical service loads were addressed utilizing an FEM approach. An FEA software, Abaqus/CAE, conducted the modeling and analysis to account for in-plane deformation and ultimate load capacity due to displacement-based cyclic load similar to that of the experimental investigation conducted in Lehigh University.

\section{Finite Element Analysis of the Flat RC Floor Slab}

The present study used the finite element approach to gather the relevant data regarding the behavior of floor diaphragms with openings using FEA, the Abaqus/CAE software. To check whether the simulation results reflect the real-world results, the flat floor slabs tested at Lehigh University in 1986 [6] were used for validation. The behavior of materials, support conditions, and loading procedures used in the experimental study by [6] was applied in the FEM. After the validation of the FEM, parametric study and sensitivity analysis were carried out by taking opening size, location, shape, service load, steel grade, and concrete grade as a parameter.

2.1. Concrete Element Types. In the present study, C3D8 (linear 8-node hexahedral brick elements) was used for modeling concrete material.

2.2. Reinforcement Bars. For elastic design analysis, the reinforcement was usually neglected in the FEM since the stiffness contribution of concrete is much greater than the reinforcement, but in the nonlinear analysis, the modeling of reinforcement is needed basically in determining the ultimate capacity of a structure. The reinforcing bars were modeled as beam elements that are one-dimensional line elements in three-dimensional space that have stiffness associated with deformation in the line. Both elastic and plastic properties were included in the elastic option used to assign the modulus of elasticity and Poisson's ratio, and in the plastic option, the true stress and strain values were used to model its plastic property. Table 1 shows the mechanical properties of reinforcing bars that were used in the simulation that was taken from the experimental study conducted by [6].

2.3. Concrete Constitutive Model. Concrete exhibits nonlinearity both in compression and tension; this poses difficulties in numerical analysis. Parameters needed to model concrete under compound stress were included in Abaqus/ CAE software in the concrete damaged plasticity (CDP) model. One of the strength hypotheses most often applied to concrete is the Drucker-Prager hypothesis. On the basis of nondilatational strain energy, failure is defined by a coneshaped boundary surface. The advantage of using this criterion is surface smoothness and thereby no complications in the numerical application. The drawback is that it is not fully consistent with the actual behavior of concrete [9]. The CDP model used in Abaqus/CAE software is a modification of the Drucker-Prager strength hypothesis. The CDP model parameters for uniaxial compression relations (Table 2) were adopted from the methods discussed by [10].

The tensile behavior of concrete utilized the bilinear model (Figure 1). The cracking opening was utilized instead of the tensile strain and was computed as a ratio of the total energy supplied $\left(G_{F}\right)$ per unit area required to create a crack in the concrete. Thus, the brittle behavior of concrete is defined by stress-cracking displacement rather than a stressstrain response [9].

Several complicated degradation mechanisms occur under uniaxial cyclic loading circumstances. Microcracks develop, close, and interact with each other. During uniaxial cyclic testing, it is noticed that the elastic stiffness recovers a little when the load changes sign. An essential element of concrete behavior under cyclic loading is the influence of stiffness recovery on the concrete's stiffness. As the load changes from tension to compression, the effect is generally more apparent, causing tensile cracks to close, resulting in the recovery of compressive stress [11].

The concrete damaged plasticity model supposes that the reduction of the elastic modulus is expressed in terms of a scalar degradation variable $(d)$ as in the following equation [11]:

$$
E=(1-d) E_{o}
$$

where $E_{o}$ is the initial (undamaged) modulus of elasticity.

In Abaqus/CAE, default values of stiffness recovery factors $w_{t}=0$ and $w_{c}=1$ were used to illustrate the uniaxial load cycle behavior of concrete. In the present study, all 
TABLE 1: The mechanical property of reinforcement bars.

\begin{tabular}{lcccccc}
\hline Name & Area $\left(\mathrm{mm}^{2}\right)$ & Yield stress $(\mathrm{MPa})$ & Yield strain & Ultimate stress $(\mathrm{MPa})$ & Ultimate strain & Modulus of elasticity $(\mathrm{GPa})$ \\
\hline D2 & 13.4 & 368 & 0.00193 & 411 & 0.00783 & 191 \\
D3 & 21.5 & 590 & 0.00272 & 590 & 0.00625 & 190 \\
\hline
\end{tabular}

TABle 2: Default parameters of the CDP model under compound stress [10].

\begin{tabular}{lc}
\hline Parameter & Value \\
\hline Dilatation angle & $36^{\circ}$ \\
Eccentricity & 0.1 \\
$f_{b o} / f_{c o}$ (ratio of biaxial to uniaxial compressive strength) & 1.16 \\
$\mathrm{~K}$ & 0.667 \\
Viscosity parameter & 0 \\
\hline
\end{tabular}

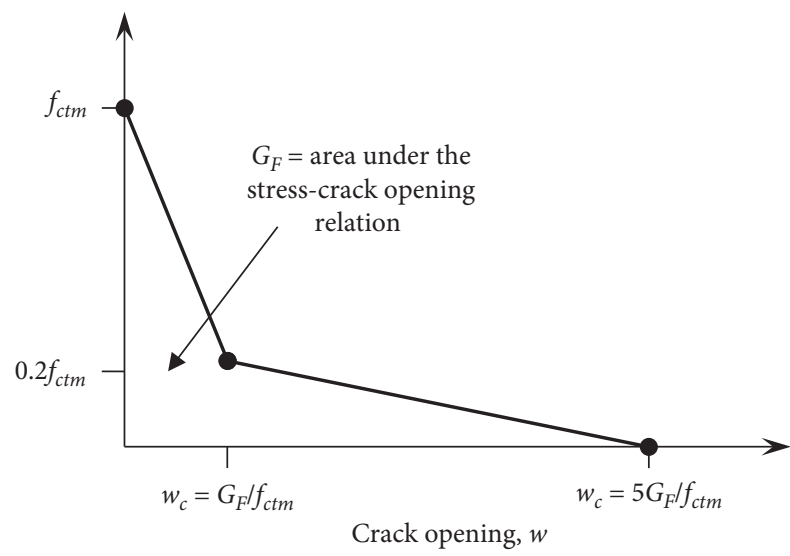

FIgURE 1: Stress-crack opening relation for uniaxial tension.

damage properties of concrete (Figure 2) were derived from a single known quantity average compressive strength of concrete $\left(f_{\mathrm{cm}}\right)$.

2.4. Finite Element Model Geometry, Mesh, and Boundary Condition. The geometrical FEM of the flat RC slab supported on the column was plotted after the material properties were defined (Figure 3 ). The slab was supported on one edge by a shear wall and the opposite edge by columns. Overhanging slabs, equal to one-quarter of the panel dimension, were added on all noncontinuous sides to represent parts of the floor slabs of adjacent bays since the test specimen by [6] represents an interior panel of a prototype building. The center-to-center span length and thickness of the RC floor slabs were $1,630 \mathrm{~mm}$ in both directions and $56 \mathrm{~mm}$, respectively, and the column dimensions were $136 \mathrm{~mm} \times 136 \mathrm{~mm}$ with no capital.

In an FEM simulation, the mesh size is an essential factor in determining the validity of the analysis results. A coarse mesh can produce less precise outcomes while the finer mesh might extend the computation cost. There is no specific regulation on the mesh size. Therefore, an iterative method was employed to find the appropriate mesh size for the model. In the present study, a mesh size of $50 \mathrm{~mm} \times 50 \mathrm{~mm}$ was appropriate to concrete and reinforcement bars generated using a mesh module (Figure 4).
The individual elements were connected properly after assembling all elements. The reinforcements were represented in the concrete region as embedded elements to ensure that the interactions between the reinforcement and concrete elements are fully bonded. The columns were directly tied to the slab using the option constraints embedment and tie.

The boundary conditions were developed using the boundary option with the initial step after the modeling and assembly of the section. The bottom surfaces of the supporting columns were fixed against all translation and rotation, and the slab nodes attached to the wall were restrained against translation in all directions (Figure 5).

2.5. Model Loading Conditions. The service gravity load was applied as a pressure force (Figure 6(a)) that was kept constant throughout the analysis, and the cyclic lateral load (Figure 6(b)) was applied with gradually increasing displacement amplitude using the loading spectrum (Figure 7) that provides more effective data regarding the hysteretic behavior of members or structures.

The vertical load applied to the RC floor slabs constituted a full-service live load of $3.8 \mathrm{kN} / \mathrm{m}^{2}$ and an additional service deal load of $3.9 \mathrm{~N} / \mathrm{m}^{2}$. A series of concentrated forces were applied, which were spaced at the center of $540 \mathrm{~mm}$ in each direction. A single vertical (gravity) load simulator controlled all point loads within one-panel width, including those in the quarter panel extension portions.

2.6. FEM Validation. The response of flat RC floor slabs without openings and slabs with different opening sizes, shapes, and locations was studied using FEM. Considering the accuracy and reliability of the numerical simulation software, the ultimate load and lateral displacement results of the flat RC floor slab in this study were extracted to verify the reliability of the model. The FEM results were compared to the experimental results obtained by [6]. The ultimate load and lateral displacement results are shown in Table 3, and the hysteretic curve for FEM and experiment results is shown in Figure 8. When the slab hysteretic curve, ultimate load, and lateral displacement obtained by FEM and experiment are compared, it is noticeable that the value estimated by the model deviates slightly from the experiment, but it is within the permissible range. Furthermore, the simulated hysteretic curve of the slab is essentially consistent with the experiment. As a result, the FEM result appears to be in excellent agreement with the experimental result.

2.7. Parametric Study of Flat RC Slabs. The parametric study examined the effects of different opening sizes, opening shapes, and opening locations of flat RC floor slabs subjected to cyclic in-plane and out-of-plane loads (Table 4). 


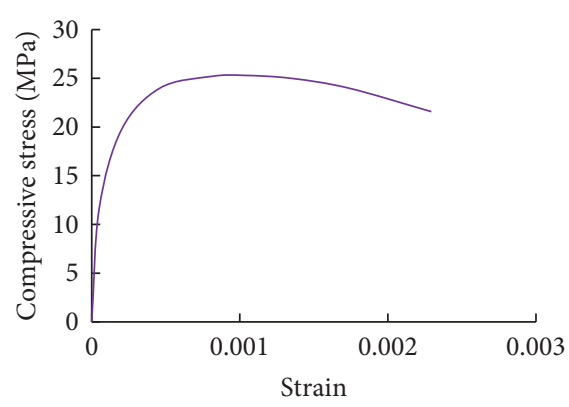

(a)

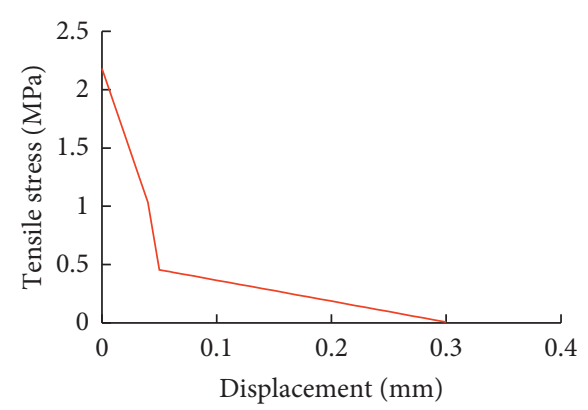

(b)

FIgURE 2: CDP model: (a) compressive behavior and (b) tensile behavior of the analyzed concrete.

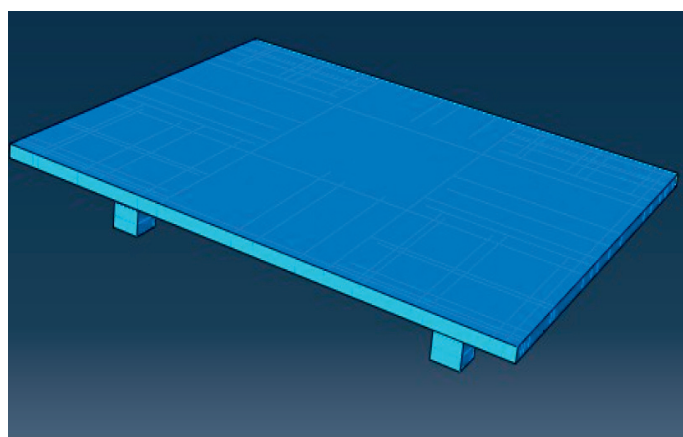

(a)

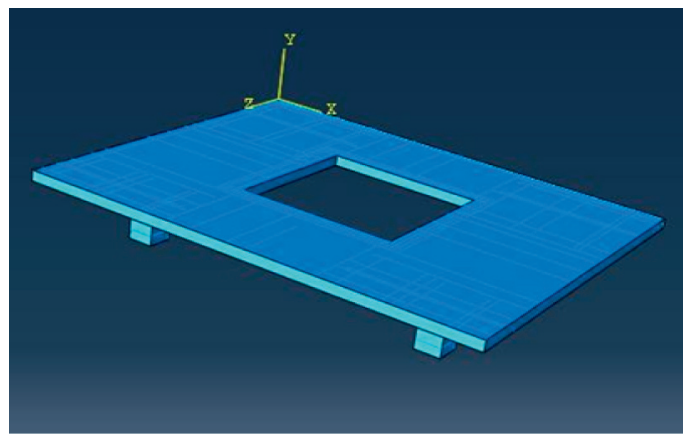

(c)

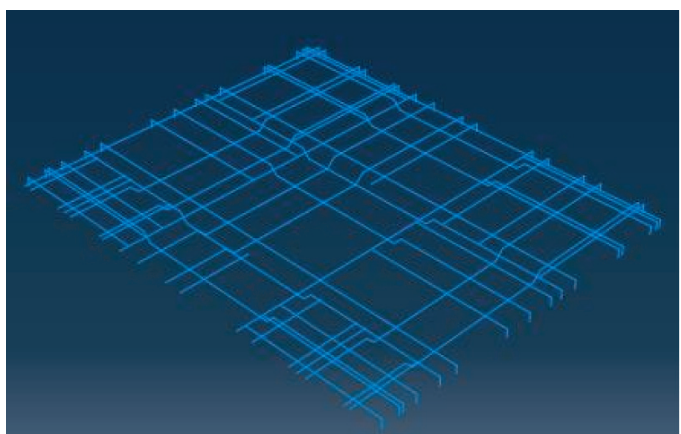

(b)

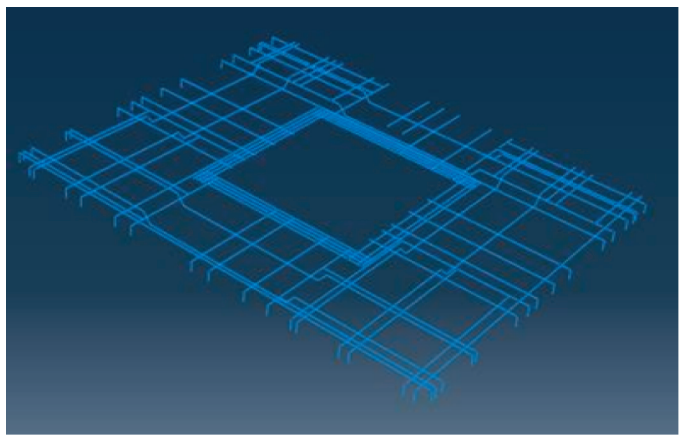

(d)

Figure 3: (a) Geometric model of a flat slab without opening, (b) embedded reinforcement of the flat slab without opening, (c) geometric model of a flat slab with opening, and (d) embedded reinforcement of the flat slab with opening.

To investigate the effect of opening size on flat RC slabs four different opening sizes were considered: $7 \%, 14 \%, 25 \%$, and $30 \%$ of the total area of the slab. These openings were placed in the middle slab area. According to [12], any size of the opening is permitted in an area that is common to the intersecting middle strips if the requirements of both strength and serviceability are satisfied. In this study, half of the interrupted reinforcements were replaced on each side of the opening to maintain the full out-of-plane capacity of the slab.

The effect of the shape of the opening was investigated by considering elliptical, circular, L-shaped, T-shaped, cross, and rectangular openings (Figure 9). These openings were $14 \%$ of the total area of the slab found at the intersection of the two middle strips of the slab.
In the present study, three opening locations were selected. These were the intersection of two middle strips, the intersection of two-column strips, and the intersection of the middle and column strip.

\section{Results and Discussion}

3.1. Effect of Opening Size on the Middle Strip of Flat RC Floor Slabs. It can be seen from Figure 10 that as opening size increases in flat RC floor slab, there is a substantial decrease in its lateral load-carrying capacity. The numerical simulation shows that the inclusion of $30 \%$ opening in the floor slab causes a $68.54 \%$ drop in lateral load-carrying capacity of the floor slab system. 


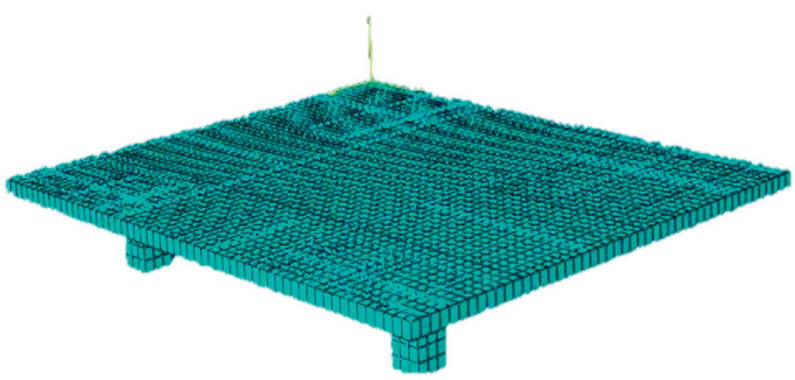

Figure 4: FEM mesh.

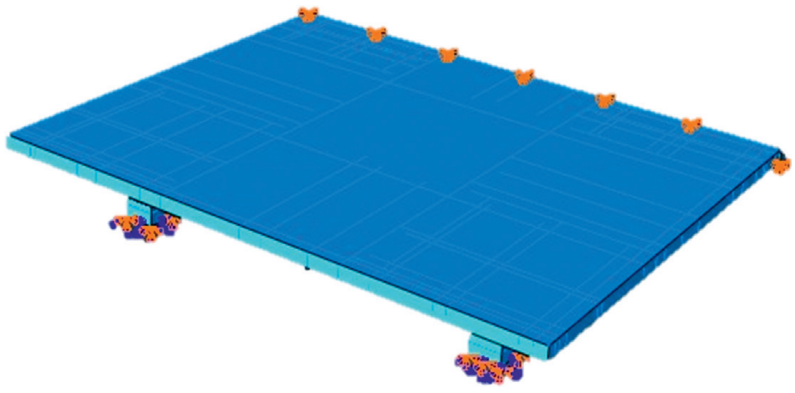

Figure 5: FEM boundary support conditions.

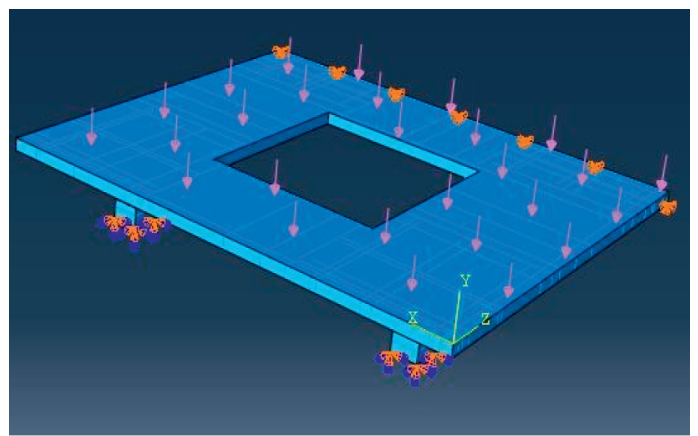

(a)

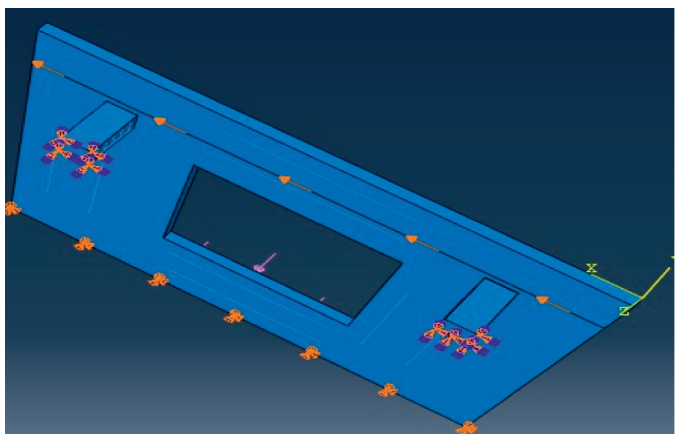

(b)

FIgURE 6: Loading conditions: (a) applied service load as a pressure and (b) applied displacement-based cyclic lateral load.

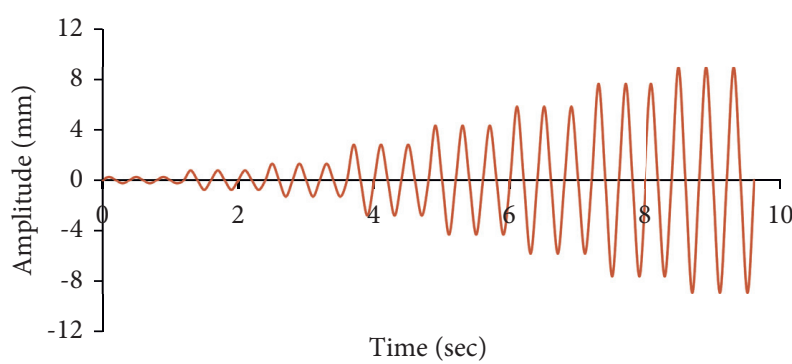

Figure 7: Cyclic loading history.

The relation between opening size and lateral loadcarrying capacity can be expressed by the following equation using nonlinear regression:

$$
y=0.095 x^{2}-5.638 x+124.87,
$$

where $y$ is the lateral load-carrying capacity $(\mathrm{kN})$ and $x$ is the opening size (\%).

Figure 11 shows that lateral displacement decreases as opening sizes increase in flat floor slabs; it can be said that solid slabs (slab without opening) show high inelastic deformation compared to the one with an opening. From the present study, it can be observed that the inclusion of $30 \%$ opening causes a drop of $45.55 \%$ in stiffness.

The relation between opening size and lateral displacement can be expressed by equation (3) using nonlinear regression:

$$
y=0.0027 x^{2}-0.164 x+5.6,
$$

where $y$ is the lateral displacement $(\mathrm{mm})$ and $x$ is the opening size (\%).

The energy absorption capacity and stiffness of the floor slab decrease as the opening size gets higher (Figure 12). 
TABLE 3: Comparison of FEM and experimental results.

\begin{tabular}{lccc}
\hline Type of test & Parameters & FEM & Experiment \\
\hline \multirow{2}{*}{ F1VCY [6] } & Ultimate load $(\mathrm{kN})$ & 101.95 & 125.67 \\
& Lateral displacement $(\mathrm{mm})$ & 4.19 & 5.61 \\
\hline
\end{tabular}

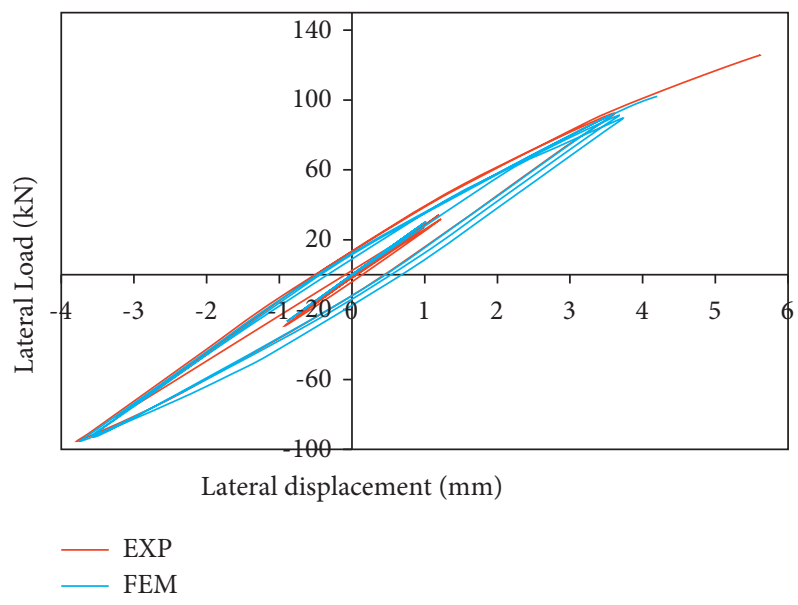

FIgURE 8: Comparison of hysteretic curves of experimental and FEM results.

TABLE 4: A summary of configurations adopted in the parametric study.

\begin{tabular}{lcc}
\hline Opening sizes $(\%)$ & Opening shapes & Opening locations \\
\hline 0 (without opening) & Elliptical & The intersection of two middle strips \\
7 & Circular & The intersection of two-column strips \\
14 & L-shaped & \\
25 & T-shaped & Cross \\
30 & Rectangular & The intersection of the middle and column strip \\
\hline
\end{tabular}

From this parametric study, the inclusion of $30 \%$ opening on the floor slab causes the drop of stiffness by $47.26 \%$.

The relation between opening size and stiffness can be expressed by equation (4) using nonlinear regression:

$$
y=-0.007 x^{2}-0.115 x+22.541
$$

where $y$ denotes stiffness $(\mathrm{kN} / \mathrm{mm})$ and $x$ denotes the opening size (\%).

\subsection{Effect of Opening Shape on the Middle Strip of Flat RC Floor} Slabs. Table 5 shows the effect of opening shapes on the middle strip lateral load-carrying capacity, lateral displacement, and stiffness of flat RC slabs. From the six types of opening shapes, a higher value of lateral load capacity and stiffness is seen in the circular opening shape. However, the cross-opening shape exhibits minimum lateral displacement.

3.3. Effect of Opening Location on Flat RC Floor Slabs. Varying the location of the opening higher value of lateral load-carrying capacity and inelastic deformation is observed when the opening is provided at the intersection of twocolumn strips of the flat RC floor slab. Reduced lateral displacement is noticed where the opening is located at the intersection of two middle strips. Table 6 illustrates the effect of different opening locations.

3.4. Sensitivity Analysis. The combinations from the Latin hypercube sampling technique were modeled in Abaqus/ CAE, and their lateral load capacity was determined (Table 7).

After the determination of the lateral load-carrying capacity, regression is done to relate the input parameters or find the correlation coefficient as follows:

$$
y=-0.383 P_{d}-2.897 O_{p}+0.458 C+0.013 S+95.767,
$$

where $y$ denotes the lateral load capacity, $P_{d}$ is the service load, $O_{p}$ is the opening size, $C$ is the compressive strength of concrete, and $S$ is the steel reinforcement strength.

From the regression analysis, it is revealed that opening size is the most influential factor in decreasing the lateral 


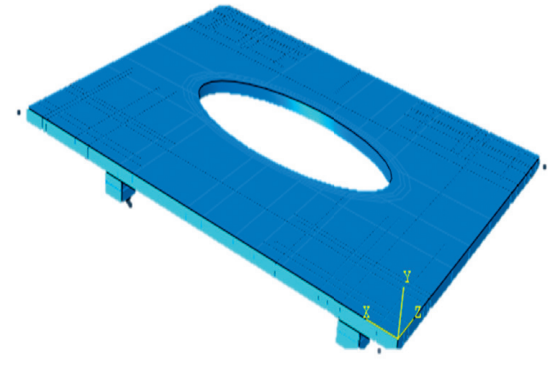

(a)

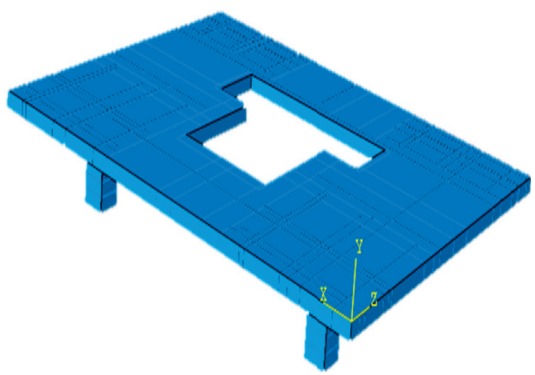

(d)

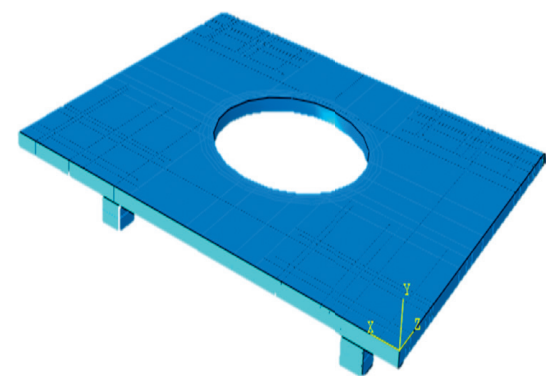

(b)

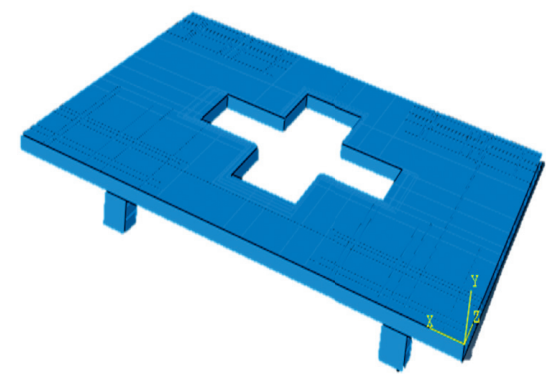

(e)

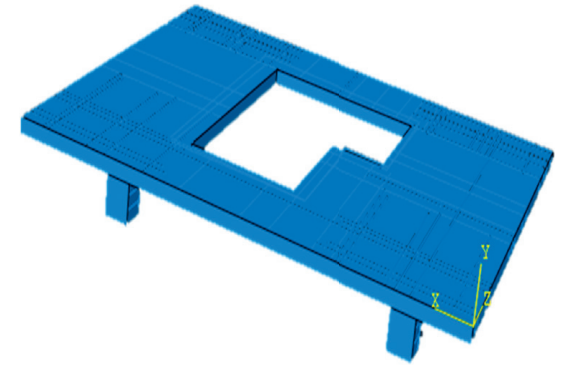

(c)

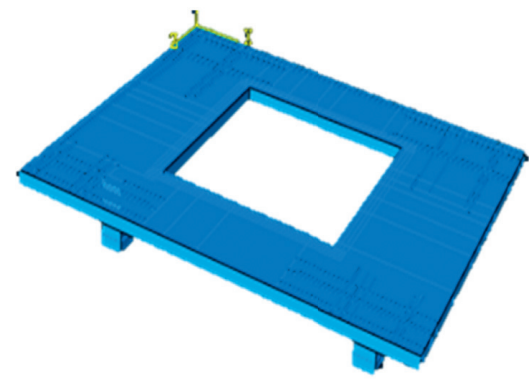

(f)

FIgURe 9: Flat RC floor slab with different opening shapes: (a) elliptical opening, (b) circular opening, (c) L-shaped opening, (d) T-shaped opening, (e) cross opening, and (f) rectangular opening.

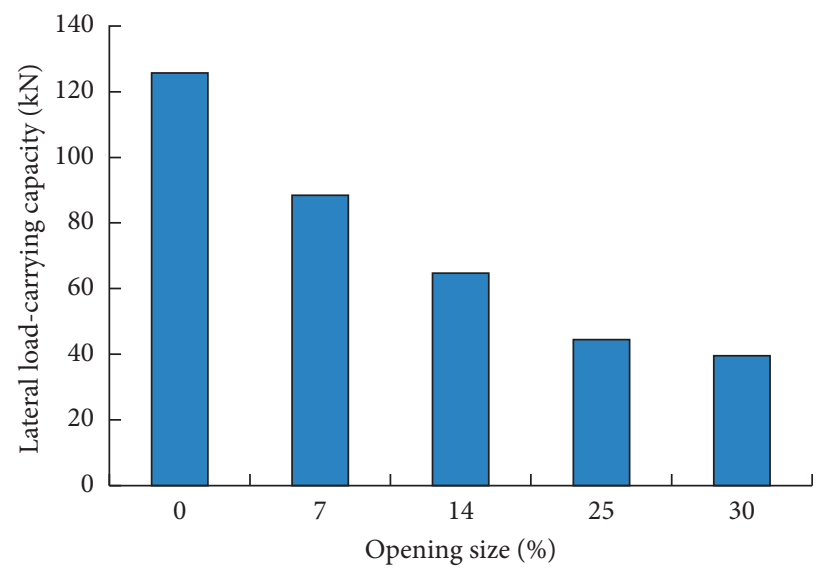

FIgURE 10: Effect of opening size on the lateral load capacity of the RC floor slab.

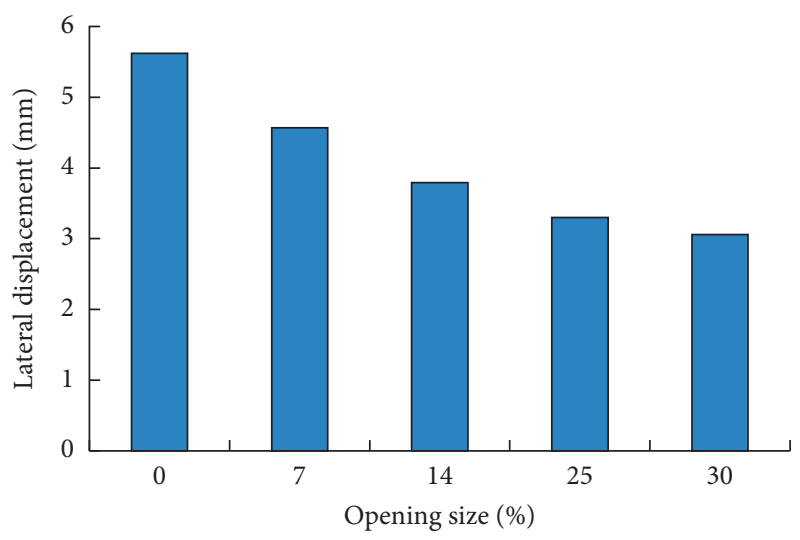

Figure 11: Effect of opening size on the lateral displacement of the floor slab. 


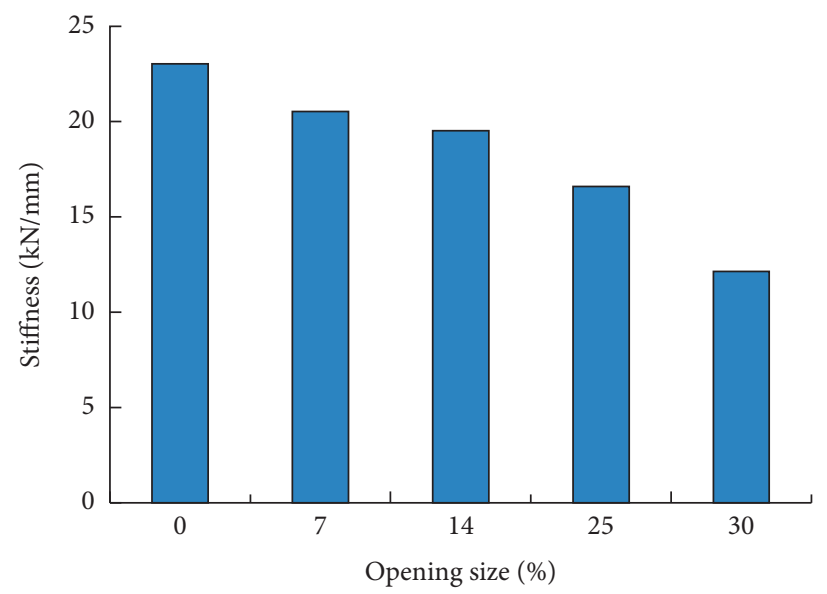

FIGURE 12: Effect of opening size on the stiffness of the floor slab.

TABLE 5: Effect of different opening shapes.

\begin{tabular}{lccc}
\hline Opening shape & Lateral load-carrying capacity $(\mathrm{kN})$ & Lateral displacement $(\mathrm{mm})$ & Stiffness $(\mathrm{kN} / \mathrm{mm})$ \\
\hline Rectangular & 64.82 & 3.30 & 19.53 \\
Elliptical & 72.62 & 3.37 & 21.50 \\
Circular & 73.77 & 3.53 & 22.49 \\
L-shaped & 55.77 & 3.43 & 17.06 \\
Cross & 68.12 & 2.71 & 20.93 \\
T-shaped & 55.60 & 3.25 & 20.75 \\
\hline
\end{tabular}

TABLE 6: Effect of different opening locations.

\begin{tabular}{lccc}
\hline Opening location & Lateral load-carrying capacity $(\mathrm{kN})$ & Lateral displacement $(\mathrm{mm})$ & Stiffness $(\mathrm{kN} / \mathrm{mm})$ \\
\hline The intersection of two middle strips & 64.82 & 3.30 & 19.53 \\
The intersection of two-column strips & 75.09 & 3.64 & 21.40 \\
Intersection of the middle and column strip & 70.33 & 3.37 & 20.54 \\
\hline
\end{tabular}

TABLE 7: The lateral load-carrying capacity of RC floor slabs from the Latin hypercube result.

\begin{tabular}{lccc}
\hline Combos & Lateral load capacity $(\mathrm{kN})$ & Combos & Lateral load capacity $(\mathrm{kN})$ \\
\hline 1 & 53.72 & 17 & 50.97 \\
2 & 43.95 & 18 & 52.17 \\
3 & 41.62 & 19 & 65.94 \\
4 & 57.15 & 20 & 54.61 \\
5 & 56.48 & 21 & 49.6 \\
6 & 52.68 & 22 & 68.21 \\
7 & 59.52 & 23 & 62 \\
8 & 56.38 & 24 & 52.89 \\
9 & 54.97 & 25 & 79.47 \\
10 & 43.37 & 26 & 64.97 \\
11 & 40.6 & 27 & 47.72 \\
12 & 50.31 & 28 & 63.13 \\
13 & 43.28 & 29 & 71.01 \\
15 & 49.19 & 30 & 51.08 \\
16 & 47.67 & 31 & 50.46 \\
\end{tabular}


load capacity of the RC floor slab since it has a higher correlation coefficient.

\section{Conclusion}

The nonlinear FEA was used to investigate the response of flat RC floor slabs subjected to cyclic in-plane loading. The influence of the slabs' aspect ratio, opening size, location, and shape was evaluated. To analyze the hysteretic behavior of concrete slabs, numerical simulation using FEA software, Abaqus/CAE, is capable of producing accurate and suitable estimations. Six types of opening shapes located on the middle panel of the floor slab were included. The energy absorption capacity and stiffness of RC floor slabs can be affected by the presence of openings. However, from these opening shapes, better energy absorption capacity and stiffness were observed in circular ones. The opening located at the intersection of two-column strips near the shear wall support showed better performance compared with the two other locations. It can be concluded that small opening sizes are recommended especially in earthquake-prone areas since the seismic capacity of the floor diaphragm is greatly affected by the presence of openings.

\section{Data Availability}

The data used to support the findings of this study are available from the corresponding author upon request.

\section{Conflicts of Interest}

The authors declare that they have no conflicts of interest.

\section{References}

[1] R. Khajehdehi and N. Panahshahi, "Effect of openings on inplane structural behavior of reinforced concrete floor slabs," Journal of Building Engineering, vol. 7, pp. 1-11, 2016.

[2] F. C. Wolfgram and B. Alireza, "Contribution of RC floor slabs in resisting lateral loads," Journal of Structural Engineering, vol. 115, no. 1, pp. 1-18, 1989.

[3] A. U. Rahman, A. Prof, and N. Jamshetty, "Seismic effect of rigid floor diaphragm," International Research Journal of Engineering and Technology, vol. 6, pp. 433-441, 2019.

[4] B. M. Moeini and B. Rafezy, "Investigation into the floor diaphragms flexibility in reinforced concrete structures and code provision," Global Journal of Researches in Engineering, vol. 11, no. 1, 2011.

[5] E. Thomas, J. George, D. Paulose, M. Tech, C. Engineering, and A. Jyothi, "Assessment of the diaphragm condition for the floor systems," International Research Journal of Engineering and Technology, vol. 4, no. 6, pp. 836-843, 2017.

[6] S. Chen, Reinforced Concrete Floor Slabs under In-Plane Monotonic and Cyclic Loading, Lehigh University, Bethlehem, PA, USA, 1986.

[7] R. Khajehdehi and N. Panahshahi, "Nonlinear FE analysis of RC building floor diaphragms with openings subjected to inplane and out-of-plane loads," in NCEE 2014 - 10th US National Conference on Earthquake Engineering Front Earthquake Engineering, p. 66045, Anchorage, Alaska, USA, July 2014.
[8] B. S. Taranath, Wind and Earthquake Resistant Buildings: Structural Analysis and Design, CRC Press, Boca Raton, FL, USA, 2004.

[9] Y. Sümer and M. Aktaş, "Defining parameters for concrete damage plasticity model," Challenge Journal of Structural Mechanics, vol. 1, no. 3, pp. 149-155, 2015.

[10] P. Kmiecik and M. Kamiński, "Modelling of reinforced concrete structures and composite structures with concrete strength degradation taken into consideration," Archives of Civil and Mechanical Engineering, vol. 11, no. 3, pp. 623-636, 2011.

[11] Abaqus/Cae, Abaqus/Cae User's Manual, Dassault Systèmes Simulia Corp., Providence, RI, USA, 2011.

[12] Aci 318 Ac, Building Code Requirements for Structural Concrete (ACI 318-05) and Commentary (ACI 318r-05), American Concrete Institute, Farmington Hills, MI, USA, 2005. 